\title{
Gordonia cholesterolivorans sp. nov., a cholesterol- degrading actinomycete isolated from sewage sludge
}

\author{
Oliver Drzyzga, J. María Navarro Llorens, Laura Fernández de las Heras, \\ Esther García Fernández and Julián Perera
}

Correspondence

Oliver Drzyzga

drzyzga@bio.ucm.es

\author{
Departamento de Bioquímica y Biología Molecular I, Universidad Complutense de Madrid, 28040 \\ Madrid, Spain
}

The genus Gordonia (formerly Gordona), proposed by Tsukamura (1971), belongs to the mycolic acid-containing group of the actinomycetes and to the suborder Corynebacterineae, which forms a distinct phyletic line in the 16S rRNA gene phylogenetic tree (Goodfellow et al., 1998; Stackebrandt et al., 1997). The suborder Corynebacterineae currently encompasses the genera Corynebacterium, Dietzia, Gordonia, Millisia, Mycobacterium, Nocardia, Rhodococcus, Segniliparus, Skermania, Smaragdicoccus, Tsukamurella and Williamsia. The members of these genera can be distinguished by using a combination of biochemical, chemical, morphological and genetic markers (Goodfellow et al., 1999; Arenskötter et al., 2004).

Gordoniae appear to be widely distributed in nature and strains have been isolated from environments such as soil, wastewater, estuary sand, mangrove rhizosphere, oilproducing wells and activated sludge foam (Takeuchi \& Hatano, 1998; Kummer et al., 1999; Kim et al., 2003; Maldonado et al., 2003; Xue et al., 2003; Shen et al., 2006; Soddell et al., 2006; Luo et al., 2007; Le Roes et al., 2008), as well as from clinical samples (Iida et al., 2005; Kageyama et al., 2006; Blaschke et al., 2007).

The GenBank/EMBL/DDBJ accession number for the $16 \mathrm{~S}$ rRNA gene sequence of strain Chol-3 ${ }^{\top}$ is EU244645.

Mycolic acid and cellular fatty acid profiles of strain $\mathrm{Chol}^{-3^{\top}}$ and related type strains of the genus Gordonia and RiboPrint data are available as supplementary materials with the online version of this paper.
The isolation of strains of the genus Gordonia with special metabolic abilities has increased the potential of applying this genus to biodegradation and bioremediation projects (Arenskötter et al., 2004). Some isolates are able to degrade xenobiotic contaminants or macromolecules such as rubber, (di)benzothiophene, 3-ethyl- and 3-methylpyridine and alkanes partially or totally (Kummer et al., 1999; Linos et al., 1999; Kim et al., 1999, 2000; Lee et al., 2001). Recently published studies have expanded the metabolic potential of the genus Gordonia, as some isolated strains metabolize butyl benzyl phthalates (e.g. Gordonia sp. MTCC 4818; Chatterjee \& Dutta, 2003) and even hazardous nitro compounds like the explosive hexahydro-1,3,5-trinitro-1,3,5-triazine (hexogen), a compound that is difficult for bacteria to degrade (e.g. Gordonia sp. KTR9; Thompson et al., 2005; Gorontzy et al., 1994). All these data show the richness of metabolic activities of gordoniae and widen our view about the possible industrial and environmental application of these bacteria.

The ability to convert steroid compounds is well documented and has been utilized by the pharmaceutical industry to synthesize novel steroid products. With the objective of finding novel and potent aerobic steroid degraders or transformers, we carried out screening experiments with cholesterol, testosterone and other steroid compounds as the only carbon and energy source for bacterial growth. A few fast-growing strains were isolated from a sewage sludge sample. The aim of this study was to clarify the taxonomic position of one of these newly 
isolated steroid-degrading strains, named strain Chol- $3^{\mathrm{T}}$, by using a polyphasic taxonomic approach.

Strain Chol- $3^{\mathrm{T}}$ was isolated from a sewage sludge sample from a wastewater treatment plant in Ciudad Real, Spain, by enriching a mixed culture in minimal medium (MM; DSMZ medium 457) broth with cholesterol as the only carbon and energy source under aerobic conditions at $30{ }^{\circ} \mathrm{C}$ in a rotary shaker $(250$ r.p.m.) for 4 days. Thereafter, strain Chol- $3^{\mathrm{T}}$ was isolated by repeatedly streaking on Luria-Bertani (LB) agar plates until a pure culture was achieved. Strain Chol $-3^{\mathrm{T}}$ was then again incubated with MM broth and cholesterol to confirm its ability to utilize cholesterol as growth substrate. Cholesterol ( $>99 \%$ purity; Sigma-Aldrich) was added to the broth directly as pure powder at a theoretical concentration of $2 \mathrm{mM}(39 \mathrm{mg}$ in $50 \mathrm{ml}$ ). Due to the very low water solubility of cholesterol, this cholesterol suspension served as a reservoir from which the bacteria could grow for a long time. The strain was maintained on LB agar plates at $4{ }^{\circ} \mathrm{C}$ for short-term storage and stored as a cell suspension in $50 \%(\mathrm{v} / \mathrm{v})$ glycerol-LB broth at $-80{ }^{\circ} \mathrm{C}$.

Bacterial biomass for chemotaxonomic and molecular biological studies was routinely obtained by growing strain Chol- $3^{\mathrm{T}}$ in LB broth in shake flasks for 2 days at $30^{\circ} \mathrm{C}$ in a rotary shaker at 250 r.p.m. The harvested cells were washed twice in distilled water for all investigations. The type strains of Gordonia sihwensis (DSM $44576^{\mathrm{T}}$ ) and Gordonia hydrophobica (DSM 44015 ${ }^{\mathrm{T}}$ ) were obtained from the DSMZ for comparative studies.

Strain Chol $-3^{\mathrm{T}}$ was tested for a broad range of phenotypic characteristics, including substrate assimilation, and the presence of mycolic acids, determined by high-temperature gas chromatography (Linos et al., 1999), and 2,6diaminopimelic acid, as described by Kim et al. (1999). The assimilation of auxonographic substrates was detected photometrically by means of reduction of the redox dye 3(4,5-dimethylthiazol-2-yl)-2,5-diphenyltetrazolium bromide. For comparative fatty acid methyl ester analysis, biomass was harvested at the late exponential growth phase. The whole-cell fatty acid composition was determined by means of capillary GC analysis and preparation was carried out using a method described by Miller \& Berger (1985).

Genomic DNA extraction and PCR-mediated amplification of the 16S rRNA gene were carried out using the procedures described by Rainey et al. (1996). To amplify the almost-complete 16S rRNA-encoding sequence (1445 nt) of strain Chol- $3^{\mathrm{T}}$, PCR primers were used with an annealing temperature of $55{ }^{\circ} \mathrm{C}$ for 30 cycles. The PCR product was purified by using the QIAquick Spin PCR purification kit (Qiagen) as described by the manufacturer. The Taq DyeDeoxy terminator cycle sequencing kit (Applied Biosystems) was used to sequence the PCR product directly according to the manufacturer's protocol. Sequence reaction mixtures were separated with an Applied Biosystems 373S DNA sequencer. The resulting 16S rRNA gene sequence was aligned with the corresponding sequences of type strains of species of the genus Gordonia with validly published names (with Williamsia serinedens IMMIB SR $-4^{\mathrm{T}}$ as the outgroup) retrieved from the GenBank/EMBL/DDBJ databases using the MEGALIGN expert sequence analysis software (version 6.1 from DNASTAR). Tree topologies were evaluated by performing neighbour-joining, maximum-parsimony and maximumlikelihood analyses with different sets of filters. Only sequences of at least $1400 \mathrm{nt}$ were used for the calculation of different trees. Tree topologies were evaluated by bootstrap analysis based on 1000 resamplings.

Spectroscopic DNA-DNA hybridization experiments were carried out in $2 \times$ SSC with $10 \%$ formamide at $70{ }^{\circ} \mathrm{C}$ between DNA extracted from strain $\mathrm{Chol}-3^{\mathrm{T}}$ and its phylogenetically closest neighbours G. sihwensis DSM $44576^{\mathrm{T}}$ and G. hydrophobica DSM $44015^{\mathrm{T}}$ according to the protocols of De Ley et al. (1970) and Huß et al. (1983). Southern hybridization experiments (Bruce, 1996; Clark, 1997) were performed on PvuII-digested chromosomal DNA of strain Chol- $3^{\mathrm{T}}$ and G. sihwensis DSM $44576^{\mathrm{T}}$ with an automated RiboPrinter system (DuPont Qualicon) using a non-radioisotopically labelled $5.5 \mathrm{~kb}$ Escherichia coli $\mathrm{rrnB}$ probe specific to the 5S-16S-23S rRNA operon. The RiboPrinter system was also used to display a similarity index of G. sihwensis DSM $44576^{\mathrm{T}}$ to strain Chol- $3^{\mathrm{T}}$ (which was set as $100 \%$, or 1.0 ) to assess the relatedness between these two strains. Both DNA-DNA hybridization and riboprinting were done by the Identification Service of the DSMZ.

Most of the morphological, physiological and chemotaxonomic characteristics of strain Chol- $3^{\mathrm{T}}$ were consistent with the diagnostic properties of the type strains of the genus Gordonia (Stackebrandt et al., 1988; Goodfellow \& Maldonado, 2006). Strain Chol- $3^{\mathrm{T}}$ shows an elementary branching rod-coccus growth cycle that is commonly found among strains of the genus Gordonia. Upon cultivation on LB agar, strain Chol- $3^{\mathrm{T}}$ exhibited beige and matt colonies. Cells were aerobic, Gram-positivestaining, non-motile and non-spore-forming.

The results of physiological tests revealed that strain Chol$3^{\mathrm{T}}$ was able to utilize a set of carbon sources that distinguish this novel isolate from closely related type strains within the genus Gordonia (Table 1). When compared to G. sihwensis DSM $44576^{\mathrm{T}}$, the most closely related strain according to $16 \mathrm{~S}$ rRNA gene sequence similarity, the substrate utilization pattern of strain Chol$3^{\mathrm{T}}$ is quite different. The two strains showed many differing characteristics; in addition to the substrates listed in Table 1 , strain Chol- $3^{\mathrm{T}}$ also utilizes acetate, $N$-acetyl-D-glucosamine, D-arabitol, cholesterol, 2-hydroxyvalerate, lactate, malate, L-proline, succinate, sucrose and turanose for growth, but not acetamide, L-alanine, L-aspartate, 3hydroxybenzoate, 4-hydroxybenzoate, myo-inositol, protocatechuate, putrescine, pyruvate, quinate, D-ribose or tyramine. 
Table 1. Carbon source utilization patterns that distinguish strain Chol- $3^{\top}$ from representatives of closely related Gordonia species

Strains: 1, strain Chol- $3^{\mathrm{T}}$; 2, G. sihwensis DSM $44576^{\mathrm{T}} ; 3$, G. hydrophobica DSM $44015^{\mathrm{T}}$; 4, G. namibiensis DSM $44568^{\mathrm{T}}$; 5 , G. hirsuta DSM $44140^{\mathrm{T}} ; 6$, G. amicalis DSM $44461^{\mathrm{T}} ; 7$, G. westfalica DSM $44215^{\mathrm{T}} ; 8$, G. bronchialis DSM $43247^{\mathrm{T}}$; 9, G. amarae DSM $43392^{\mathrm{T}}$. Data for reference type strains were taken from Kim et al. (2003). ND, No data available.,$+ \mathrm{OD}_{540}>0.13 ;-, \mathrm{OD}_{540} \leqslant 0.13$.

\begin{tabular}{|lccccccccc|}
\hline Carbon source & $\mathbf{1}$ & $\mathbf{2}$ & $\mathbf{3}$ & $\mathbf{4}$ & $\mathbf{5}$ & $\mathbf{6}$ & $\mathbf{7}$ & $\mathbf{8}$ & $\mathbf{9}$ \\
\hline 4-Aminobutyrate & - & + & - & - & $\mathrm{ND}$ & - & - & - & $\mathrm{ND}$ \\
Benzoate & + & - & - & - & - & - & + & - & - \\
Caprate & - & + & - & - & $\mathrm{ND}$ & + & + & + & $\mathrm{ND}$ \\
Citrate & - & + & + & - & - & + & + & - & + \\
D-Galactose & - & + & + & + & + & + & - & + & + \\
Glucarate & + & - & + & - & - & + & - & - & - \\
Gluconate & - & + & - & + & - & + & - & + & - \\
D-Glucosaminic acid & - & + & - & - & - & + & + & - & - \\
L-Leucine & - & + & + & - & - & + & - & + & - \\
2-Oxoglutarate & - & + & + & - & + & + & + & - & + \\
Phenylacetate & + & + & - & - & - & + & - & + & - \\
Pimelate & - & + & - & - & - & + & - & - & - \\
L-Rhamnose & + & - & + & - & - & + & - & + & - \\
L-Serine & - & + & + & + & - & + & - & - & - \\
L-Valine & - & + & + & - & - & - & - & + & + \\
& & & & & & & & & \\
\hline
\end{tabular}

The chemotaxonomic characteristics of strain Chol- $3^{\mathrm{T}}$ were also consistent with its classification in the genus Gordonia (Goodfellow \& Maldonado, 2006). The wholecell hydrolysate of the isolate contained meso-diaminopimelic acid as the only diamino acid of the peptidoglycan and arabinose and galactose as major cell-wall sugars, which places strain Chol- $3^{\mathrm{T}}$ in cell-wall chemotype IV according to Lechevalier \& Lechevalier (1970). The main mycolic acid components of strain Chol- $3^{\mathrm{T}}$ and some Gordonia type strains are listed in Supplementary Table S1 (available in IJSEM Online). The organism possesses shortchain mycolic acids, ranging in length from $\mathrm{C}_{48}$ to $\mathrm{C}_{56}$, which is comparable with only a few other members of the genus Gordonia and sets it close to G. sihwensis, Gordonia amarae, Gordonia amicalis and Gordonia shandongensis. Most of the Gordonia type strains possess long-chain mycolic acids, ranging in length from $\mathrm{C}_{54}$ to $\mathrm{C}_{64}$.

The fatty acid pattern of strain Chol- $3^{\mathrm{T}}$ contained straightchain saturated and unsaturated fatty acids plus tuberculostearic acid (10-methyl $\mathrm{C}_{18: 0}$ ) (Supplementary Table S2). The major fatty acids were $\mathrm{C}_{16: 1}$ cis7 $(14 \%), \mathrm{C}_{16: 0}(37 \%)$, $\mathrm{C}_{18: 1}(24 \%)$ and 10-methyl $\mathrm{C}_{18: 0}(16 \%)$. Although this pattern, with major proportions of palmitic $\left(\mathrm{C}_{16: 0}\right)$, oleic $\left(\mathrm{C}_{18: 1}\right)$ and tuberculostearic acids, is quite similar to those of all Gordonia species, there are qualitative and quantitative species-specific differences. As can be seen in Supplementary Table S2, the novel isolate contained a relatively large proportion of $\mathrm{C}_{16: 1}$ cis 7 , a fatty acid that
Gordonia westfalica and Gordonia bronchialis also contain as a major component. All other type strains of Gordonia that have been described so far show minor proportions or the complete absence of this fatty acid.

The assignment within the genus was also confirmed by 16S rRNA gene sequence analysis. The almost-full-length $16 \mathrm{~S}$ rRNA gene sequence (1445 bp) of strain Chol- $3^{\mathrm{T}}$ was used for BLAST searches against the GenBank/EMBL/DDBJ databases, which showed that this strain is related to members of the genus Gordonia with an intrageneric relatedness ranging from 91.8 to $99.8 \%$ sequence similarity. Strain Chol- $3^{\mathrm{T}}$ lay in a monophyletic clade together with G. sihwensis DSM $44576^{\mathrm{T}}$, G. hydrophobica DSM $44015^{\mathrm{T}}$ and $G$. shandongensis $\mathrm{SD} 29^{\mathrm{T}}$ in the neighbourjoining tree (Fig. 1) and shared the highest gene sequence similarity with these strains $(99.8,95.7$ and $95.4 \%$, respectively).

The phenotypic properties of strain Chol- $3^{\mathrm{T}}$ and its closest neighbour in the phylogenetic tree, G. sihwensis DSM $44576^{\mathrm{T}}$, clearly demonstrate the differences between these two strains. In contrast to G. sihwensis DSM $44576^{\mathrm{T}}$, it is very interesting that strain Chol- $3^{\mathrm{T}}$ is a foam-producing bacterium when grown in rich media, a characteristic that is well-known for G. amarae (Iwahori et al., 2001; Pagilla et al., 2002; Carr et al., 2006) and that has also recently been found for Gordonia defluvii and other Gordonia species (Soddell et al., 2006; Shen et al., 2007). More differences between strain Chol- $3^{\mathrm{T}}$ and G. sihwensis can also be found in colony colour and form. The novel isolate produces beige and matt colonies on agar plates, whereas the colonies of G. sihwensis are white and rough (Kim et al., 2003).

Additionally, the completely different RiboPrint patterns of these two strains presented in Supplementary Fig. S1 clearly show that these strains are not identical. The comparison of PvuII-digested and probe-hybridized DNA of the two strains shows bands with different sizes for the two strains and the similarity index was only about 0.54 for $G$. sihwensis DSM $44576^{\mathrm{T}}$ when compared directly with strain Chol $-3^{\mathrm{T}}$. Thus, the patterns demonstrated that strain Chol$3^{T}$ does not represent a subspecies of G. sihwensis. Finally, analysis of DNA-DNA relatedness between strain Chol- $3^{\text {T }}$ and its two phylogenetically closest neighbours in the $16 \mathrm{~S}$ rRNA gene tree, G. sihwensis DSM $44576^{\mathrm{T}}$ and $G$. hydrophobica DSM $44015^{\mathrm{T}}$, revealed values of $8.9 \pm 0.7 \%$ and $8.8 \pm 3.0 \%$, respectively; these values are well below the $70 \%$ cut-off point recommended by Wayne et al. (1987) for the recognition of genomic species.

It is evident from the above-mentioned data that the tested organism can be distinguished from the type strains of all Gordonia species with validly published names. It is, therefore, clear from both genotypic and phenotypic results that strain $\mathrm{Chol}-3^{\mathrm{T}}$ should be recognized as a member of a novel species within the genus Gordonia, for which the name Gordonia cholesterolivorans sp. nov. is proposed. The degradation of cholesterol by a member of 


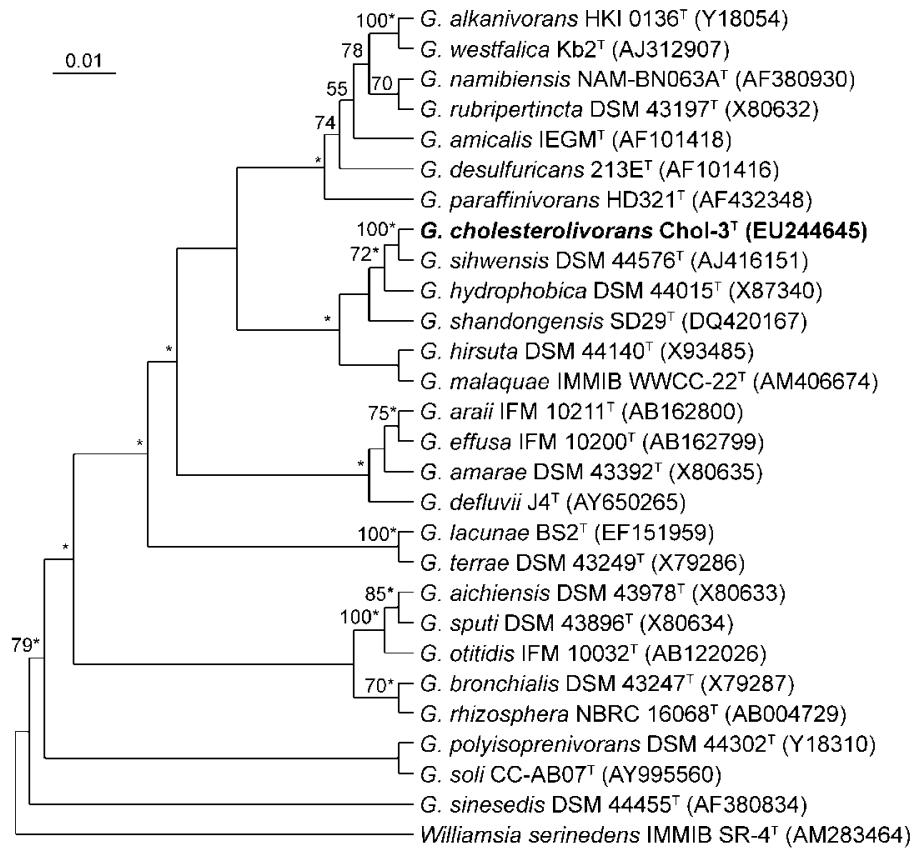

Fig. 1. Neighbour-joining tree based on almost-complete 16S rRNA gene sequences showing the phylogenetic position of strain Chol- $3^{\top}$ within the genus Gordonia. The outgroup used to root the tree was Williamsia serinedens IMMIB SR $-4^{\top}$. Asterisks indicate branches that were also recovered using the maximum-likelihood and maximum-parsimony tree-making algorithms. Numbers at nodes are percentage bootstrap values; only values above $50 \%$ are given. Bar, 0.01 substitutions per nucleotide position. the genus Gordonia is here demonstrated for the first time. This broadens the range of metabolic potential of this genus and therefore makes it more attractive for environmental and industrial applications.

\section{Description of Gordonia cholesterolivorans sp. nov.}

Gordonia cholesterolivorans (cho.les'te.ro.li.vo'rans. N.L. n. cholesterol cholesterol; L. part. adj. vorans eating, devouring; N.L. part. adj. cholesterolivorans cholesterol-devouring).

Gram-positive-staining, aerobic, non-motile, slightly acidfast actinomycete that fragments into rod/coccus-like elements. Colonies are beige and matt on LB agar plates. The steroid cholesterol is utilized as a sole carbon and energy source for aerobic growth in MM. Additional properties such as carbon utilization and cell-wall characteristics are mentioned in the text and in Table 1 . Hydrolyses the chromogenic substrates p-nitrophenyl phosphorylcholine and 2-deoxythymidine- 5 '-p-nitrophenyl phosphate, but not $p$-nitrophenyl $\beta$-D-xyloside. The major fatty acids are $\mathrm{C}_{16: 1}$ cis7, $\mathrm{C}_{16: 0}, \mathrm{C}_{18: 1}$ and 10-methyl $\mathrm{C}_{18: 0}$. Possesses short-chain mycolic acids ranging in length from $\mathrm{C}_{48}$ to $\mathrm{C}_{56}$, with $\mathrm{C}_{50}, \mathrm{C}_{52}$ and $\mathrm{C}_{54}$ being the principal mycolic acids.

The type strain, Chol- $3^{\mathrm{T}}\left(=\mathrm{CECT} 7408^{\mathrm{T}}=\mathrm{DSM} 45229^{\mathrm{T}}\right)$, was isolated from sewage sludge from a sewage treatment plant in Ciudad Real, Spain.

\section{Acknowledgements}

We thank Julio M. Rubio Aranda for the sewage sludge sample from which strain Chol- $3^{\mathrm{T}}$ was isolated. We thank the DSMZ for technical support. O. D. is contracted by the Spanish Ministry of Education and Science in the programme 'Ramón y Cajal' (co-financed by the
European Social Fund). This work was supported by grants from the Spanish Ministry of Education and Science (project BFU2006-15214C03-02).

\section{References}

Arenskötter, M., Bröker, D. \& Steinbüchel, A. (2004). Biology of the metabolically diverse genus Gordonia. Appl Environ Microbiol 70, 3195-3204.

Blaschke, A. J., Bender, J., Byington, C. L., Korgenski, K., Daly, J., Petti, C. A., Pavia, A. T. \& Ampofo, K. (2007). Gordonia species: emerging pathogens in pediatric patients that are identified by $16 \mathrm{~S}$ ribosomal RNA gene sequencing. Clin Infect Dis 45, 483-486.

Bruce, J. (1996). Automated system rapidly identifies and characterizes microorganisms in food. Food Technol 50, 77-81.

Carr, E. L., Eales, K. L. \& Seviour, R. J. (2006). Substrate uptake by Gordonia amarae in activated sludge foams by FISH-MAR. Water Sci Technol 54(1), 39-45.

Chatterjee, S. \& Dutta, T. K. (2003). Metabolism of butyl benzyl phthalate by Gordonia sp. strain MTCC 4818. Biochem Biophys Res Commun 309, 36-43.

Clark, C. G. (1997). Riboprinting: a general tool for the study of genetic diversity in microorganisms. J Eukaryot Microbiol 44, 277-283.

De Ley, J., Cattoir, H. \& Reynaerts, A. (1970). The quantitative measurement of DNA hybridization from renaturation rates. Eur $J$ Biochem 12, 133-142.

Goodfellow, M. \& Maldonado, L. A. (2006). The families Dietziaceae, Gordoniaceae, Nocardiaceae and Tsukamurellaceae. In The Prokaryotes, 3rd edn, vol. 3, pp. 843-888. Edited by F. Dworkin, S. Falkow, K. H. Schleifer \& E. Stackebrandt. New York: Springer.

Goodfellow, M., Alderson, G. \& Chun, J. (1998). Rhodococcal systematics: problems and developments. Antonie van Leeuwenhoek 74, 3-20.

Goodfellow, M., Isik, K. \& Yates, E. (1999). Actinomycete systematics: an unfinished synthesis. Nova Acta Leopold 312, 47-82. 
Gorontzy, T., Drzyzga, O., Kahl, M. W., Bruns-Nagel, D., Breitung, J., von Löw, E. \& Blotevogel, K. H. (1994). Microbial degradation of explosives and related compounds. Crit Rev Microbiol 20, 265-284.

Huß, V. A. R., Festl, H. \& Schleifer, K. H. (1983). Studies on the spectrophotometric determination of DNA hybridization from renaturation rates. Syst Appl Microbiol 4, 184-192.

lida, S., Taniguchi, H., Kageyama, A., Yazawa, K., Chibana, H., Murata, S., Nomura, F., Kroppenstedt, R. M. \& Mikami, Y. (2005). Gordonia otitidis sp. nov., isolated from a patient with external otitis. Int J Syst Evol Microbiol 55, 1871-1876.

Iwahori, K., Tokutomo, T., Imbata, N. \& Fujita, M. (2001). Formation of stable foam by the cells and culture supernatant of Gordonia (Nocardia) amarae. J Biosci Bioeng 92, 77-79.

Kageyama, A., lida, S., Yazawa, K., Kudo, T., Suzuki, S., Koga, T., Saito, H., Inagawa, H., Wada, A. \& other authors (2006). Gordonia araii sp. nov. and Gordonia effusa sp. nov., isolated from patients in Japan. Int J Syst Evol Microbiol 56, 1817-1821.

Kim, S. B., Brown, R., Oldfield, C., Gilbert, S. C. \& Goodfellow, M. (1999). Gordonia desulfuricans sp. nov., a benzothiophene-desulphurizing actinomycete. Int J Syst Bacteriol 49, 1845-1851.

Kim, S. B., Brown, R., Oldfield, C., Gilbert, S. C., lliarionov, S. \& Goodfellow, M. (2000). Gordonia amicalis sp. nov., a dibenzothiophene-desulphurizing actinomycete. Int J Syst Evol Microbiol 50, 2031-2036.

Kim, K. K., Lee, C. S., Kroppenstedt, R. M., Stackebrandt, E. \& Lee, S. T. (2003). Gordonia sihwensis sp. nov., a novel nitrate-reducing bacterium isolated from a wastewater-treatment bioreactor. Int J Syst Evol Microbiol 53, 1427-1433.

Kummer, C., Schumann, P. \& Stackebrandt, E. (1999). Gordonia alkanivorans sp. nov., isolated from tar-contaminated soil. Int J Syst Bacteriol 49, 1513-1522.

Lechevalier, M. P. \& Lechevalier, H. (1970). Chemical composition as a criterion in the classification of aerobic actinomycetes. Int J Syst Bacteriol 20, 435-443.

Lee, J. J., Rhee, S. K. \& Lee, S. T. (2001). Degradation of 3methylpyridine and 3-ethylpyridine by Gordonia nitida LE31. Appl Environ Microbiol 67, 4342-4345.

Le Roes, M., Goodwin, C. M. \& Meyers, P. R. (2008). Gordonia lacunae sp. nov., isolated from an estuary. Syst Appl Microbiol 31, 17-23.

Linos, A., Steinbüchel, A., Spröer, C. \& Kroppenstedt, R. M. (1999). Gordonia polyisoprenivorans sp. nov., a rubber-degrading actinomycete isolated from an automobile tyre. Int J Syst Bacteriol 49, 1785-1791.

Luo, H., Gu, Q., Xie, J., Hu, C., Liu, Z. \& Huang, Y. (2007). Gordonia shandongensis sp. nov., isolated from soil in China. Int J Syst Evol Microbiol 57, 605-608.

Maldonado, L. A., Stainsby, F. M., Ward, A. C. \& Goodfellow, M. (2003). Gordonia sinesedis sp. nov., a novel soil isolate. Antonie van Leeuwenhoek 83, 75-80.
Miller, L. \& Berger, T. (1985). Bacterial identification by gas chromatography of whole cell fatty acids. Application note 228-241. Palo Alto, CA: Hewlett-Packard.

Pagilla, K. R., Sood, A. \& Kim, H. (2002). Gordonia (Nocardia) amarae foaming due to biosurfactant production. Water Sci Technol 46(1-2), 519-524.

Rainey, F. A., Ward-Rainey, N., Kroppenstedt, R. M. \& Stackebrandt, E. (1996). The genus Nocardiopsis represents a phylogenetically coherent taxon and a distinct actinomycete lineage: proposal of Nocardiopsaceae fam. nov. Int J Syst Bacteriol 46, 1088-1092.

Shen, F. T., Goodfellow, M., Jones, A. L., Chen, Y. P., Arun, A. B., Lai, W. A., Rekha, P. D. \& Young, C. C. (2006). Gordonia soli sp. nov., a novel actinomycete isolated from soil. Int J Syst Evol Microbiol 56, 2597-2601.

Shen, F. T., Huang, H. R., Arun, A. B., Lu, H. L., Lin, T. C., Rekha, P. D. \& Young, C. C. (2007). Detection of filamentous genus Gordonia in foam samples using genus-specific primers combined with PCRdenaturing gradient gel electrophoresis analysis. Can J Microbiol 53, $768-774$.

Soddell, J. A., Stainsby, F. M., Eales, K. L., Seviour, R. J. \& Goodfellow, M. (2006). Gordonia defluvii sp. nov., an actinomycete isolated from activated sludge foam. Int J Syst Evol Microbiol 56, 2265-2269.

Stackebrandt, E., Smida, J. \& Collins, M. D. (1988). Evidence of phylogenetic heterogeneity within the genus Rhodococcus: revival of the genus Gordona (Tsukamura). J Gen Appl Microbiol 34, 341-348.

Stackebrandt, E., Rainey, F. A. \& Ward-Rainey, N. L. (1997). Proposal for a new hierarchic classification system, Actinobacteria classis nov. Int J Syst Bacteriol 47, 479-491.

Takeuchi, M. \& Hatano, K. (1998). Gordonia rhizosphera sp. nov. isolated from the mangrove rhizosphere. Int J Syst Bacteriol 48, 907912.

Thompson, K. T., Crocker, F. H. \& Fredrickson, H. L. (2005). Mineralization of the cyclic nitramine explosive hexahydro-1,3,5trinitro-1,3,5-triazine by Gordonia and Williamsia spp. Appl Environ Microbiol 71, 8265-8272.

Tsukamura, M. (1971). Proposal of a new genus, Gordona, for slightly acid-fast organisms occurring in sputa of patients with pulmonary disease and in soil. J Gen Microbiol 68, 15-26.

Wayne, L. G., Brenner, D. J., Colwell, R. R., Grimont, P. A. D., Kandler, O., Krichevsky, M. I., Moore, L. H., Moore, W. E. C., Murray, R. G. E. \& other authors (1987). International Committee on Systematic Bacteriology. Report of the ad hoc committee on reconciliation of approaches to bacterial systematics. Int J Syst Bacteriol 37, 463-464.

Xue, Y., Sun, X., Zhou, P., Liu, R., Liang, F. \& Ma, Y. (2003). Gordonia paraffinivorans sp. nov., a hydrocarbon-degrading actinomycete isolated from an oil-producing well. Int J Syst Evol Microbiol 53, 1643-1646. 